\title{
DKK1 is a potential novel mediator of cisplatin-refractoriness in non-small cell lung cancer cell lines
}

\author{
Hogir Salim, Dali Zong, Petra Hååg, Metka Novak, Birgitta Mörk, Rolf Lewensohn, Lovisa Lundholm*† \\ and Kristina Viktorsson ${ }^{*+}$
}

\begin{abstract}
Background: Platinum compounds are the mainstay of chemotherapy for lung cancer. Unfortunately treatment failure remains a critical issue since about $60 \%$ of all non-small cell lung cancer (NSCLC) patients display intrinsic platinum resistance.

Methods: We analyzed global gene expression profiles of NSCLC clones surviving a pulse treatment with cisplatin and mapped deregulated signaling networks in silico by Ingenuity Pathway Analysis (IPA). Further validation was done using siRNA.

Results: The pooled cisplatin-surviving NSCLC clones from each of the biological replicates demonstrated heterogeneous gene expression patterns both in terms of the number and the identity of the altered genes. Genes involved in Wnt signaling pathway (Dickkopf-1, DKK1), DNA repair machinery (XRCC2) and cell-cell/cell-matrix interaction (FMN1, LGALS9) were among the top deregulated genes by microarray in these replicates and were validated by q-RT-PCR. We focused on DKK1 which previously was reported to be overexpressed in NSCLC patients. IPA network analysis revealed coordinate up-regulation of several DKK1 transcriptional regulators (TCF4, EZH2, DNAJB6 and HDAC2) in cisplatin-surviving clones from that biological replicate. Knockdown of DKK1 by siRNA sensitized for cisplatin in two different NSCLC cell lines and in ovarian A2780 cells, but not in the A2780 cis subline made resistant to cisplatin by chronic exposure, suggesting a role of $D K K 1$ in intrinsic but not acquired platinum refractoriness.
\end{abstract}

Conclusions: We identified DKK1 as a possible marker of a cisplatin-refractory phenotype and as a potential novel therapeutic target to improve platinum response of NSCLC cells.

\section{Background}

Lung cancer (LC) is the tumor type with the highest number of cancer-associated deaths worldwide [1]. LC is histologically categorized into non-small cell lung cancer (NSCLC) and small cell lung cancer (SCLC) of which NSCLC constitutes about $85 \%$ of all cases and is further divided into adeno-, squamous cell- and large cell carcinoma [1]. Surgery, if possible, is the treatment of choice for stage I, II and IIIa NSCLC with chemotherapy primarily being used as adjuvant or neoadjuvant treatment [2]. For non-resectable or advanced NSCLC, which constitutes the majority of

\footnotetext{
* Correspondence: Lovisa.Lundholm@su.se; Kristina.Viktorsson@ki.se

${ }^{\dagger}$ Equal contributors

Karolinska Biomics Center, Department of Oncology-Pathology, Karolinska Institutet, SE-171 76 Stockholm, Sweden
}

cases, multimodal chemotherapy alone or in combination with radiotherapy is the main treatment option [2]. The chemotherapy regimen usually consists of a cisplatin or a carboplatin doublet combined with gemcitabine, vinorelbine, paclitaxel, pemetrexed or docetaxel [2]. The primary mechanism of cisplatin action at clinically relevant doses is to induce DNA damage. This is achieved through covalent crosslinking of platinum to the cellular DNA, leading to the formation of crosslinks in the same DNA strand (intra-strand crosslink) or between the two different strands, so called inter-strand crosslinks, ICLs [3]. Subsequently, the ICLs physically impede the progress of the replication fork and transcriptional machinery causing replication stress and blocked transcription process, leading to activation of the intra-S checkpoint, and if the lesions are too extensive, induction of cell death [3]. 
Cisplatin resistance is still a major obstacle for the clinical management of NSCLC. At the molecular level, a cisplatin-refractory phenotype can be a result of: (I) failure to reach the DNA (pre-target resistance), (II) impeded induction of DNA lesions (on-target resistance), (III) malfunctioning of cell death pathways (post-target resistance), and (IV) activation of pro-survival signaling pathways that are not directly influenced by cisplatin, but abolish its death-inducing capacity (off-target resistance), reviewed in [4].

Although the molecular mechanisms underlying cisplatin refractoriness have been investigated for over a decade, only two biomarkers that can predict cisplatin sensitivity and distinguish responders from non-responders have reached the clinic, excision repair cross-complementing rodent repair deficiency, complementation group 1 (ERCC1) and ribonucleotide reductase M1 (RRM1), respectively. NSCLC cases whose specimen lacked ERCC1 expression had a more prominent response to adjuvant cisplatin treatment and hence ERCC1 expression holds promise as a predictive biomarker. [5]. Low RRM1 mRNA expression was linked to a better response to a cisplatin/gemcitabine regimen [6]. However, neither ERCC1 nor RRM1 were correlated to cisplatin sensitivity when basal mRNA expression was analyzed in 12 NSCLC cell lines [7] reflecting the complexity in finding biomarkers which can predict cisplatin responsiveness.

Other studies have aimed to characterize signaling cascades which could drive cisplatin-survival and hence constitute putative resistance-driving networks in lung cancer by focusing on short term effects of continuous cisplatin treatment i.e. from hours up to a few days, or by creating resistant sub-lines after repeated cisplatin pressure which also could generate new driving mutations $[4,8]$. In this study, we explored the intrinsic properties of the cisplatinsurviving sub-population of NSCLC cells 9 days after a single one hour-treatment. This treatment regimen was chosen to reflect the short pulse of drug used clinically, where administration time is typically 30 minutes to two hours (http://www.cisplatin.org/treat.htm).

Using this approach, we found a heterogeneous gene expression pattern when analyzing three biological replicates of cisplatin-surviving NSCLC clones. Among the different biological replicates we identified genes in diverse cellular pathways in these cisplatin-survivors e.g. dickkopf-1 (DKK1), X-ray repair cross-complementing protein 2 (XRCC2), formin 1 (FMN1) and lectin, galactoside-binding, soluble 9 (LGALS9). Through bioinformatics analysis, we identified TCF4, EZH2, DNAJB6 and $H D A C 2$ as co-regulated, upstream regulators of DKK1, which may form a signaling circuit that enhances the effect of $D K K 1$ in enabling survival after cisplatin treatment. By siRNA-mediated knockdown of DKK1 in NSCLC and ovarian cancer cells, the colony forming capacity and/or cell survival upon cisplatin treatment was reduced significantly. In contrast, plasmid-based overexpression of FMN1 did not clearly increase cisplatin sensitivity of NSCLC cells. Thus our data suggest that DKK1 should be further explored as a potential biomarker of cisplatin refractoriness and/or as a target for cisplatinsensitizing strategies in NSCLC and other tumor types.

\section{Methods}

\section{Cell lines and culture conditions}

In the present study human NSCLC cell lines U-1810 and U-1752 (gifts from Uppsala University, Sweden [9]), A549, H23, H125, H157, H661 and H1299 (ATCC, Manassas, VA, USA) were used. Cells were cultured at $37^{\circ} \mathrm{C}$ and $5 \% \mathrm{CO}_{2}$ in RPMI- 1640 medium containing $2 \mathrm{mM}$ L-glutamine, supplemented with $10 \%$ heat-inactivated fetal bovine serum (both from Invitrogen, Stockholm, Sweden). In addition, the human ovarian cancer cell lines A2780 and its cisplatin-resistant subline A2780 cis (Sigma-Aldrich, Stockholm, Sweden) were used and cultured as above. To maintain the cisplatin resistance of A2780 cis cells, $1 \mu \mathrm{M}$ cisplatin was added to the culture medium every $3^{\text {rd }}-4^{\text {th }}$ passage. All cell lines used in the study were established and already published on (see above). No ethical permits were therefore required for their use in the current study.

\section{Colony formation assay of cisplatin-refractory NSCLC clones}

NSCLC cells were seeded in duplicate in Cell + culture dishes (Sarstedt, Landskrona, Sweden) at a density of 500 cells $/ 100 \mathrm{~mm}$ dish and were after $24 \mathrm{~h}$ treated with cisplatin (2.5-20 $\mu \mathrm{M}$, Hospira Nordic AB, Stockholm, Sweden) for one hour. Cells were rinsed in PBS after treatment and allowed to form colonies over a 9-days period. The resulting colonies were visualized by staining with crystal violet $(0.5 \%$ crystal violet in $25 \%$ methanol) or collected for RNA extraction (see below). For clonogenic survival analyses, colonies consisting of at least 50 cells were counted under a light microscope using duplicate plates from three independent experiments. For retreatment experiments, cell colonies were instead trypsinized and pooled, counted and seeded in 96-well plates for MTT or in new Cell + plates for treatment the next day using the same setup as in the first treatment.

\section{RNA extraction and gene expression analysis}

In order to have enough RNA for the gene expression analysis all the surviving clones from each biological replicate were pooled and subjected to total RNA extraction using Trizol (Invitrogen) as described [10]. Cleanup was performed using the RNeasy Mini kit (Qiagen, Sollentuna, Sweden) and RNA quality was analyzed using an Agilent 2100 Bioanalyzer (Agilent, Santa Clara, CA, 
USA). Analysis of gene expression was performed using Affymetrix ${ }^{\circ}$ whole transcript GeneChip ${ }^{\circ} \mathrm{Hu}$ man Gene 1.0 ST arrays (Affymetrix, Santa Clara, CA, USA), which contains probes for 28869 genes. cDNA was prepared from 500 ng total RNA, labeled and hybridized to arrays using standard protocols (http:// www.affymetrix.com/support/technical/product_updates/ wt_1_1_assay.affx). Primary array processing was performed using the Affymetrix GeneChip ${ }^{\circ}$ Command Console $^{\circ}$ Software (AGCC, version 1.1) and subsequent analysis was conducted using the Affymetrix Expression Console (EC, version 1.1).

Post-acquisition data processing was carried out using previously described methods (http://www.affymetrix.com/ estore/browse/level-1-instruments-software-landingpage.jsp?expand=true\&parent $=35854 \&$ category $=35919$ ).

Briefly, probe logarithmic intensity error estimation (PLIER) was used to enhance probe signals by summarization; perfect match GC composition-based background correction (PM GCBG) was applied for background correction and global median to normalize the signals. For further analysis, genes with signal intensity below 10 after background correction were excluded to avoid taking genes whose alterations are not easily distinguished from noise into subsequent analyses. In addition, genes corresponding to uncharacterized proteins, hypothetical proteins prefixed with the letters LOC, and small nucleolar RNAs $(S N O R D)$ were also excluded from the analysis since in this study we aimed to focus on well annotated, proteincoding mRNAs. The raw data presented and used in this article is deposited in NCBI's Gene Expression Omnibus (GEO) [11] as described in the Availability of supporting data section. Hierarchical clustering analysis was performed using Partek Genomics Suite version 6.6 (Partek Inc., St. Louis, MO, USA) in which clustering was based on rows and columns using Euclidean distance for row/column dissimilarity and average linkage as row/column method.

\section{Quantitative real-time PCR (q-RT-PCR)}

For the q-RT-PCR validation of gene expression data, $500 \mathrm{ng}$ of the same RNA batch was used as template for cDNA synthesis using Reverse Transcription Reagents with random hexamer primers (Applied Biosystems, Stockholm, Sweden) as previously described [12]. To quantify mRNA expression levels, cDNA, Fast SYBR ${ }^{\circ}$ Green Master Mix (Applied Biosystems) and the following primers (DKK1, forward: CGG GAA TTA CTG CAA AAA TGG AAT ATG TG, reverse: AAG CTT TCA GTG ATG GTT TCC TCA ATT; XRCC2, forward: GGC GAT GTG TAG TGC CTT CCA TA, reverse: TTT CTT TCA AGG AAC TTC TAC CTT CAA GTC; LGALS9, forward: AGC TCC AGT GGA ACC AGG TTT G, reverse: TCA TTT CCA CTG AAG CCA GTC
TGA A; ERCC1, forward: CTG CTT GTC CAG GTG GAT GTG AAA, reverse: GAT ACA CAT CTT AGC CAG CTC CTT GAG. RRM1, forward: CCT ATG AGG GCT CTC CAG TTA GCA A, reverse: CCA GTC CCA TAG GTC TGT AGG AGT AAC; 18S, forward: GCT TAA TTT GAC TCA ACA CGG GA, reverse: AGC TAT CAA TCT GTC AAT CCT GTC C) (from DNA technology, Risskov, Denmark) or FMN1 (cat.\# QT01330315, Qiagen) were mixed in a final volume of $10 \mu \mathrm{l}$. The Fast PCR program was used on the ABI Prism 7900HT Sequence detection system (Applied Biosystems), which is initiated at $95{ }^{\circ} \mathrm{C}$ for $20 \mathrm{~s}$, followed by 45 amplification cycles $\left(95{ }^{\circ} \mathrm{C}, 1 \mathrm{~s} ; 60{ }^{\circ} \mathrm{C}, 20 \mathrm{~s}\right)$. For each biological sample two technical replicates were used and the relative RNA expression obtained by applying the $2^{-\Delta \Delta \mathrm{Ct}}$ method [13] in which 18S rRNA was used as an internal control.

\section{Immunoblotting}

Proteins were extracted using RIPA buffer containing $50 \mathrm{mM}$ Tris- $\mathrm{HCl}, \mathrm{pH}$ 7.4, $150 \mathrm{mM} \mathrm{NaCl}, 1 \mathrm{mM}$ EDTA, $0.1 \%$ Na-deoxycholate and $1 \%$ NP-40. Thirty microgram of total protein was loaded onto ready-to-use 4-12\% Bis-Tris gels (NuPAGE, Invitrogen), separated by electrophoresis and thereafter blotted onto nitrocellulose membrane (Trans-Blot, Bio-Rad, Hercules, CA, USA). After blocking in Odyssey blocking buffer, diluted 1:1 with TBST (LI-COR Biosciences, Lincoln, NE, USA), primary antibodies recognizing phosphoserine 9 GSK3B, phosphoserine 473 AKT, total AKT and PI3-kinase (5558, 9271, 4685 and 4257, respectively, Cell Signaling Technology, Danvers, MA, USA), p21 ${ }^{\text {WAF1/Cip1 }}$ or Bcl-2 (sc-756 and sc-509, Santa Cruz Biotechnology, Dallas, TX, USA) was added. To control for loading differences, GAPDH (ab9484, Abcam, Cambridge, UK) or $\beta$-tubulin (Sigma-Aldrich) was used. To visualize primary antibody binding on the membranes, secondary goat-anti-mouse or goat-anti-rabbit antibodies directly conjugated to infrared dyes, IRDye (LI-COR Biosciences) were applied and resulting protein expression levels analyzed by the Odyssey ${ }^{\circ} \mathrm{Sa}$ Infrared Imaging System (LI-COR Biosciences).

\section{Ingenuity Pathway Analysis}

Ingenuity Pathway Analysis tool (IPA; Ingenuity Systems, Redwood city, CA) was used to create in silico interaction networks of $D K K 1$ based on published, publically available data, showing direct upstream transcription regulators of $D K K 1$ as well as proteins downstream of $D K K 1$.

\section{MTT cell viability assay}

To assess cytotoxic response of cisplatin, MTT (3-[4,5dimethylthiazol-2-yl]-2,5-diphenyl-tetrazolium) cell viability assay was used in a 96-well format as previously described [14]. Three technical replicates were made for each biological sample and assayed after a continuous 
exposure to cisplatin for $72 \mathrm{~h}$. For NSCLC cells, 5000 cells/well were used and in A2780 and A2780 cis experiments, 15000 cells were seeded per well. Cell viability was assessed by adding the MTT reagent as indicated [14] and is given as \% of untreated cells whose viability was set to $100 \%$. For the NSCLC cells, cisplatin sensitivity was calculated using the area under curve (AUC) from the survival curve.

\section{DKK1 siRNA transfection}

To inhibit DKK1 expression in U-1810, A549 and A2780/ A2780 cis cells, $50 \mathrm{nM}$ siRNA against $D K K 1$ (si1 = s22721: Sense: GCU UCA CAC UUG UCA GAG Att, Antisense: UCU CUG ACA AGU GUG AAG Cct; si2=s22722: Sense: GGC UCU CAU GGA CUA GAA Att, Antisense: UUU CUA GUC CAU GAG AGC Ctt, Invitrogen) or non-targeting siRNA (NT, 4390843, Invitrogen) was added to the cells during $72 \mathrm{~h}$ (U-1810, A549) or $96 \mathrm{~h}$ (A2780, A2780 cis) using Dharmafect 1 (0.1 \%) from Dharmacon (Thermo Scientific, Lafayette, CO, USA). Cells were subsequently detached and frozen for RNA extraction or were re-plated for cell death and signaling profiling analysis (collected 24-72 h after cisplatin exposure), for MTT or for colony formation capacity after cisplatin treatment.

\section{Overexpression of FMN1 and assessment of cisplatin sensitivity}

FMN1 was overexpressed in U-1810 cells by transfecting cells with the FMN1 open reading frame cDNA integrated in the pCMV6-AC-GFP plasmid (OriGene, Rockville, Maryland, USA), using Lipofectamine LTX reagent (Invitrogen, Germany). Briefly, U1810 cells were seeded in 6-well plates and transfected with $2 \mu \mathrm{g}$ of pCMV6-AC-GFP FMN1 plasmid for $24 \mathrm{~h}$. As a control, cells only treated with Lipofectamine were used. The next day, media was removed, and normal growth media (RPMI-1640) was added to each well for another $24 \mathrm{~h}$. Western blot analysis was used to confirm the overexpression of FMN1 at the point of cisplatin treatment using a FMN1 antibody (Abcam, Cambridge, UK). To assess the effect on proliferation and cisplatin sensitivity, cells were seeded in 96 -well plates (8000 cells/well), and the next day treated with indicated concentrations of cisplatin for $72 \mathrm{~h}$. The cytotoxicity of cisplatin was determined with (3-[4,5-dimethylthiazol-2-yl]-2,5-diphenyl-tetrazolium) (MTT) assay as described above. Survival of cells is given by comparing the absorbance in treated cells relative to the absorbance in cells only treated with Lipofectamine. Three separate transfections were performed with triplicate technical repeats in the MTT. Data presented is the mean \pm SEM.

\section{Statistical analysis}

Data given is the mean \pm S.D. from three separate experiments, unless otherwise indicated. A two-tailed unpaired Student's t-test was used. $P<0.05$ was considered for statistical significance.

\section{Results \\ Cisplatin-refractory NSCLC surviving clones show a heterogeneous gene expression pattern}

In order to identify underlying signaling aberrations of the NSCLC cells which could govern a cisplatinrefractory phenotype, the gene expression pattern of long-term cisplatin-surviving NSCLC clones was analyzed in three biological replicates and compared with that of untreated cells which formed colonies, as outlined in Fig. 1a. First, cytotoxic profiling of NSCLC U-1810 cells after cisplatin treatment was carried out using concentrations in the range achievable in plasma from patients $(5 \mu \mathrm{M})$ [15] (Fig. 1b). The U1810 cells displayed a clear cisplatin-refractory phenotype as $2.5,5$ and $10 \mu \mathrm{M}$ cisplatin only reduced the colony forming capacity by $10 \%$, while at $20 \mu \mathrm{M}$ cisplatin, the reduction was $20 \%(p=0.02)$ (Fig. 1b). Although the difference in clonogenicity was minor, $10 \mu \mathrm{M}$ cisplatin caused a 2-fold decrease in total cell number (Fig. 1c). This demonstrates that at therapeutically relevant concentrations, the reduction in growth rate is more pronounced than the effects on colony number after platinum treatment.

Next we pooled the surviving NSCLC clones from untreated or cisplatin-treated cells within each biological replicate and performed gene expression array analysis. First, we sought to identify genes which were consistently altered in all three biological replicates examined using a cutoff value of 1.5 -fold up- or down-regulated. From this analysis only one gene, formin 1 (FMN1), previously reported to control cell morphology by regulating focal adhesion and motility [16], was regulated in all replicates. Despite similar treatment conditions in the three biological replicates of cells, yet they showed some differences in cisplatin response (Fig. 1b).

We reasoned that as cisplatin may confer resistance in multiple ways, the heterogeneity among the biological replicates could possibly reflect a biologically heterogeneous response but it cannot be ruled out that also experimental variations by other means could contribute to the observed results. As a next step we therefore analyzed alterations in gene expression in each biological replicate separately. In total, 2720 genes were up- and 2725 genes were down-regulated in the cisplatinsurviving clones from the first replicate, while 1238 and 50 genes were up- and 46 and 84 genes were downregulated in the surviving clones from the second and third replicates, respectively (Table 1). Importantly, the 

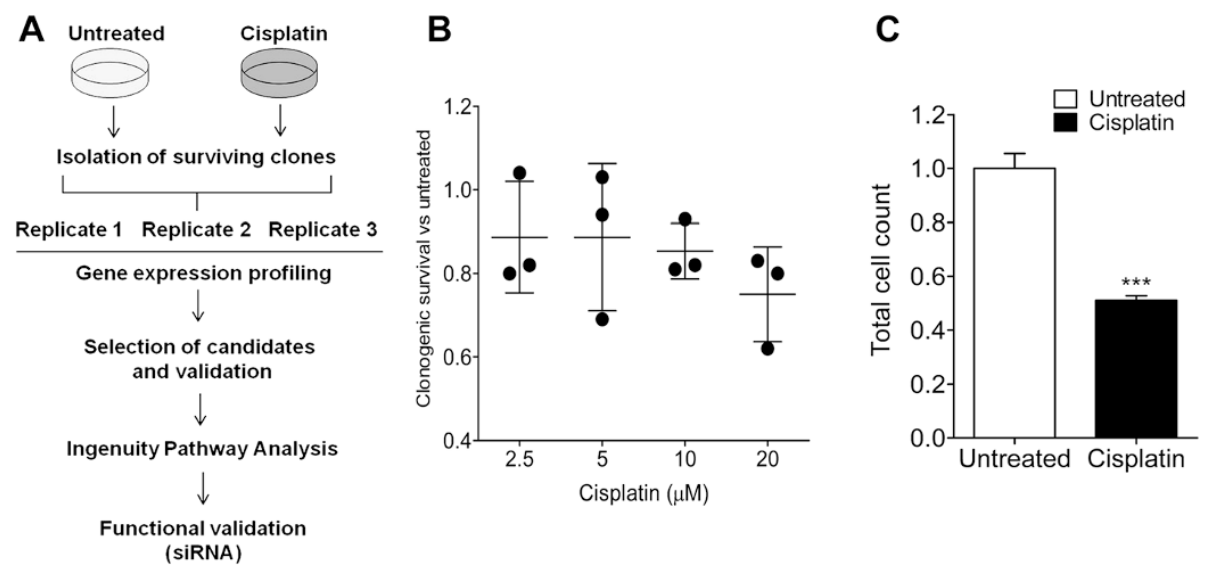

Fig. 1 Colony formation assay after treatment of U-1810 cells with cisplatin. a Schematic outline of the experiments. NSCLC U-1810 cells were either untreated or cisplatin-treated for $1 \mathrm{~h}$. Cells were then allowed to form colonies over 9 days in drug-free media. One set of dishes was stained with $0.5 \%$ crystal violet and the number of colonies was counted. Other sets of dishes were used for extraction of total RNA for gene expression profiling. Ingenuity Pathway Analysis software was used to identify altered cellular networks based on differential gene expression (>1.5 fold up- or down-regulated) relative to untreated cells. A number of genes were selected for further validation by q-RT-PCR. $\mathbf{b}$ Relative clonogenic survival of NSCLC U-1810 cells after treatment with 2.5-20 $\mu \mathrm{M}$ cisplatin. For each concentration, three biological replicates were performed where the survival of untreated cells was set to one. $\mathbf{c}$ Total cell number was calculated using a haemocytometer for the surviving clones after $10 \mu \mathrm{M}$ cisplatin. ${ }^{* * *} ; p<0.005$

difference in direction of regulation, magnitude as well as in the number of altered genes among the three biological replicates varied (Additional file 1, Table 1). This suggests that there is indeed considerable heterogeneity among the surviving NSCLC clones on the transcriptome level, which also was evident by hierarchical clustering (Additional file 1).

By analyzing each biological replicate separately a number of genes with altered expression in cisplatinsurviving NSCLC clones as compared to untreated counterparts were evident. Among the top 10 regulated genes from the cisplatin-refractory NSCLC clones were dickkopf-1 (DKK1) and X-ray repair cross-complementing protein 2 (XRCC2) from the first replicate, and lectin, galactoside-binding, soluble 9 (LGALS9) from the third replicate (Fig. 2, labeled with *). These proteins have been implicated in the prognosis of different tumors [17-19]. DKK1 is a secreted protein that inhibits bone formation

Table 1 Number of regulated genes in cisplatin-surviving clones

\begin{tabular}{lll}
\hline & \multicolumn{2}{l}{ No. of genes $(\geq 1.5$-fold $)$} \\
\cline { 2 - 3 } & Up-regulated genes & Down-regulated genes \\
\hline Replicate 1 & 2720 & 2725 \\
Replicate 2 & 1238 & 46 \\
Replicate 3 & 50 & 84 \\
Replicate 1 2 & 19 & 8 \\
Replicate 1+3 & 9 & 11 \\
Replicate 2 +3 & 7 & 0 \\
Replicate $1+2+3$ & 0 & 1 \\
\hline
\end{tabular}

The numbers of differentially expressed genes in each replicate of the NSCLC residual U-1810 clones after cisplatin treatment. through inhibition of Wnt signaling pathway and has been shown to be highly expressed in NSCLC tumor material and serum from NSCLC patients as compared to patients with no tumor $[18,20]$. DKK1 has also been shown to promote invasion and migration in NSCLC cells in vitro [21]. In our gene expression analysis, DKK1 was 24-fold higher expressed in the cisplatin-refractory clones than in the untreated clones in that biological replicate (Fig. 2, top panel).

In accordance with other studies which demonstrated a role of homologous recombination (HR) in interstrand crosslink tolerance [19], we observed an 8-fold up-regulation of XRCC2 in cisplatin-refractory NSCLC clones. Finally, in the third biological replicate LGALS9 expression was 1.7-fold higher in residual NSCLC clones than in untreated clones (Fig. 2, lower panel). LGALS9 is a member of beta-galactoside-binding proteins (galectins) and has been described to be a negative regulator of the antitumor immune $\mathrm{T}$ cells [17]. Importantly, although we found that each of these genes were up-regulated in different biological replicates of cisplatin-refractory NSCLC residual clones, their expression levels were largely unchanged in the other replicates further illustrating that the NSCLC residual clones that survive cisplatin pulse treatment have heterogeneous gene expression patterns.

Validation of altered FMN1, DKK1, XRCC2 and LGALS9 mRNA expression in cisplatin-refractory NSCLC residuals

Next, we set out to validate the observed alterations in FMN1, DKK1, XRCC2 and LGALS9 expression by q-RTPCR using the same RNA as was applied in the 


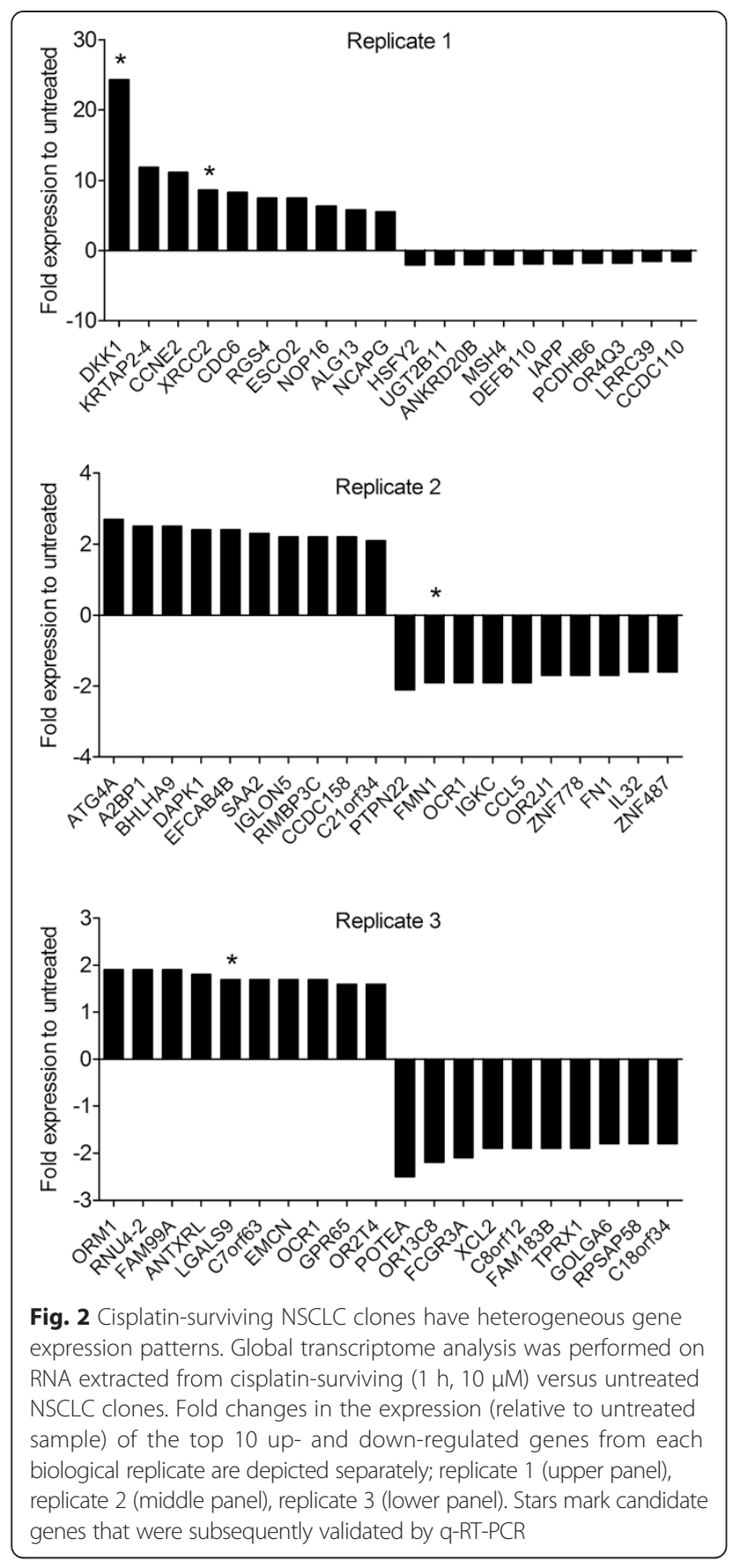

microarray analysis (Fig. 3). In the global transcriptome analysis, FMN1 expression was reduced in the cisplatin-surviving NSCLC residual clones by about $50 \%$ (Fig. 3a, left panel). Accordingly, q-RT-PCR revealed a similar down regulation of FMN1 mRNA expression in all three replicates confirming the observed alteration of this gene in cisplatin-refractory clones (Fig. 3a, right panel). We also tested if overexpression of FMN1 in NSCLC U-1810 cells could sensitize for cisplatin treatment (Additional file 2). Albeit a clear overexpression of
FMN1 was achieved (Additional file 2A) and FMN1 alone caused a slight decrease in cell viability, no statistically significant effect on cisplatin response was evident (Additional file 2B). Hence this data suggest that the observed down regulation of FMN1 in cisplatin refractory clones is not directly associated with resistance, or acts in concert with other signaling components in order to regulate cisplatin responsiveness.

$D K K 1$, the top scored gene in the first biological replicate showed a 25 -fold increase in the cisplatin-refractory clones by global gene expression profiling and a 15-fold up-regulation by q-RT-PCR analysis (Fig. 3b). In addition, XRCC2 expression was increased about 10-fold when analyzed by either microarray or q-RT-PCR, in replicate 1 (Fig. 3b). Finally, LGALS9 expression was 1.7 -fold higher in NSCLC cisplatin-refractory clones as analyzed by microarray and similarly 1.4-fold higher than untreated cells by q-RT-PCR in replicate 3 (Fig. $3 \mathrm{~b}$ ). In conclusion, we were able to validate the altered expression of FMN1, $D K K 1, X R C C 2$ and LGALS9 observed with gene expression profiling.

\section{DKK1 pathway proteins show concurrent up-regulation in} cisplatin-refractory NSCLC clones

To further explore the $D K K 1$ pathway in the cisplatinrefractory phenotype of NSCLC cells and to delineate putative mechanisms, Ingenuity Pathway Analysis (IPA) was used to map upstream regulating and downstream proteins of DKK1 (Fig. 4). First, an interaction network based on published literature composed of proteins regulating $D K K 1$ was created and from this the transcriptional regulators of $D K K 1$ were selected for further analysis (Fig. 4a). In total, IPA identified 16 transcriptional regulators of $D K K 1$ out of which 4 showed a concurrent up-regulation in the NSCLC cisplatin-surviving clones (Fig. 4a). Thus the expression of transcription factor 4 (TCF4), enhancer of zeste homolog 2 (EZH2), DnaJ homolog subfamily B member 6 (DNAJB6) and histone deacetylase 2 (HDAC2) showed 2.0-, 3.0-, 1.6and 2.3-fold increase, respectively, in the cisplatin refractory NSCLC clones relative to the corresponding untreated clones of replicate 1 . The finding that different factors in the $D K K 1$ pathway are coordinately up-regulated in cisplatin-surviving NSCLC clones may point towards a role for $D K K 1$ in driving a cisplatinrefractory phenotype.

In order to identify signaling components downstream of DKK1 which could have a role in the control of a cisplatin-refractory phenotype, a similar network was constructed by IPA. Albeit some direct protein-protein interactions are reported, only indirect targets of DKK1 were available in IPA. Cyclin-dependent kinase inhibitor 1A (CDKN1A, also called p21 $\left.{ }^{\mathrm{WAF} 1 / \mathrm{Cip} 1}\right)[22,23]$, microtubule-associated protein tau (MAPT) [24-26], 

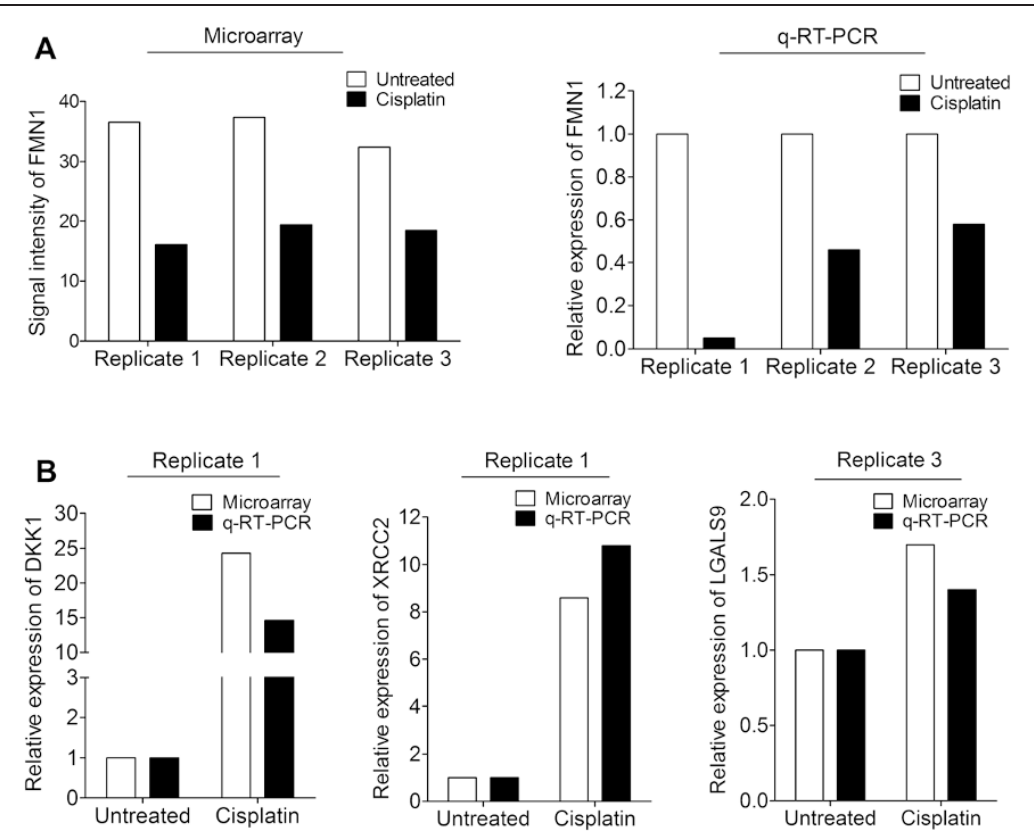

Fig. 3 Validation of potential markers for intrinsic cisplatin refractoriness by q-RT-PCR. a Expression levels of FMN1 in cisplatin-surviving clones from all three biological replicates were determined by microarray analysis (left panel) and q-RT-PCR (right panel). b Relative mRNA expression of DKK1, XRCC2 and LGALS9 was determined by q-RT-PCR from replicates 1 and 3, respectively. For all mRNA analyses, 18S rRNA was used to control for loading differences among the samples. The relative expression of each gene in cisplatin-surviving NSCLC residual clones is given as fold change relative to untreated NSCLC clones which are set to one

mitogen-activated protein kinase 1 (MAPK1, ERK2) [27], disks large homolog 4 (DLG4) [28], glycogen synthase kinase 3 beta $(G S K 3 B)[28,29]$ and ephrin type$\mathrm{B}$ receptor 2 (EPHB2) [30] were found to be indirectly regulated by $D K K 1$ and could therefore potentially be mediators of the DKK1 effect (Fig. 4b). GSK3B, which is reported to be a master negative regulator of diverse signaling pathways including Wnt and insulin signaling [31], displayed a 1.5 -fold increased expression in replicate 1. DLG4, which encodes a neuronal signaling and cell polarity protein with a potential tumor suppressor role [32], was 1.8-fold down-regulated in replicate 1 . The other reported $D K K 1$ downstream proteins displayed only minor changes in mRNA expression in NSCLC cisplatinrefractory clones indicating that these are not downstream targets in this setting (for deposited data, see Availability of supporting data).

\section{Basal DKK1 expression does not correlate to cisplatin sensitivity}

Given the observed up-regulation of $D K K 1$ in cisplatinrefractory NSCLC residual clones, we next analyzed basal mRNA DKK1 expression levels in NSCLC cell lines with the aim to reveal if there was a correlation between basal DKK1 expression level and cisplatin sensitivity (Fig. 4c). A heterogeneous expression level of DKK1 was evident among the NSCLC cell lines with the highest DKK1 mRNA expression found in A549 and H23 cells, which displayed an about 80- and 30-fold higher expression than that observed in the U-1810 cells, which were used for the gene expression profiling of residual clones (Fig. 4c, left panel). We next set out to analyze if there was a correlation between basal DKK1 expression on mRNA level and cisplatin responsiveness. The NSCLC were subjected to $72 \mathrm{~h}$ continuous treatment with cisplatin and the area under the curve (AUC) was used as a measurement of cisplatin sensitivity. No correlation between baseline DKK1 expression and platinum sensitivity was however evident (Fig. 4c, right panel). Of note, the cisplatin sensitivity was relatively similar for the NSCLC cell lines which potentially could explain the lack of correlation between $D K K 1$ and cisplatin response Moreover, the mRNA levels of the previously published markers of cisplatin resistance, $R R M 1$ and ERCC1, were also analyzed in relation to cisplatin responsiveness (Fig. 4d-e). Their expression was generally much less diverse than DKK1 in our NSCLC cell line panel (Fig. 4d-e), and not correlated to their platinum sensitivity.

\section{Ablation of DKK1 expression sensitizes NSCLC cells to cisplatin}

In order to functionally connect $D K K 1$ expression to cisplatin response we next analyzed the effect of cisplatin on DKK1 expression in NSCLC U-1810 cells at 48 and $72 \mathrm{~h}$ after a $1 \mathrm{~h}$ pulse treatment with $10 \mu \mathrm{M}$ cisplatin (Fig. 5a). As shown in Fig. 5a, transient cisplatin 
A

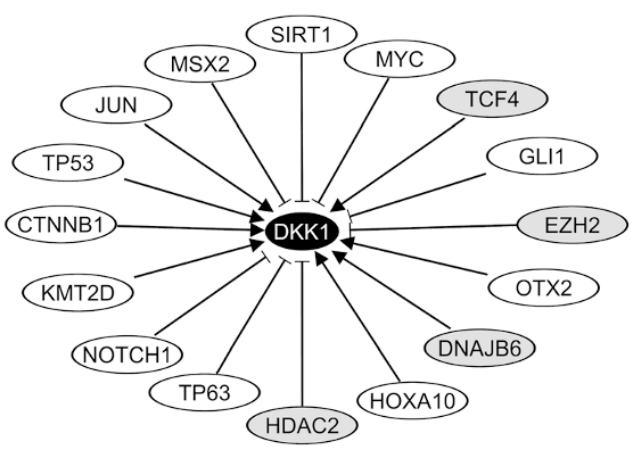

B

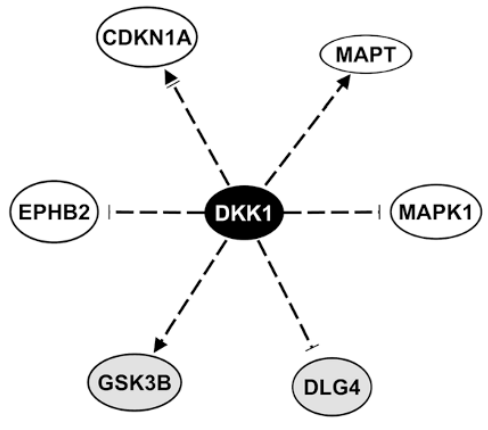

C
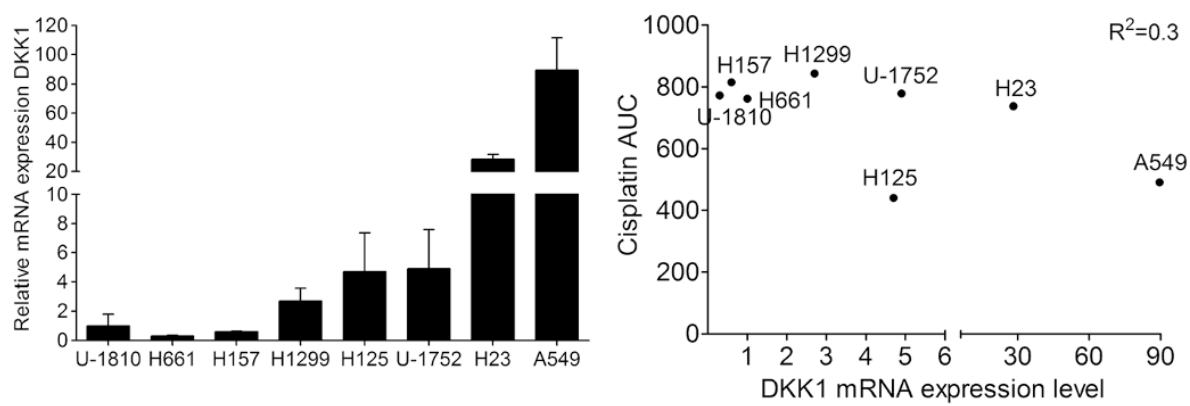

D
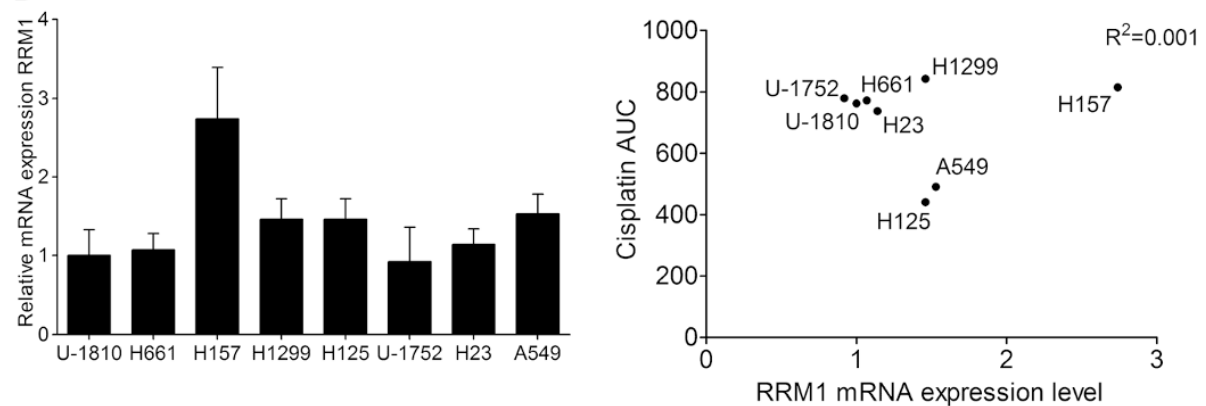

E
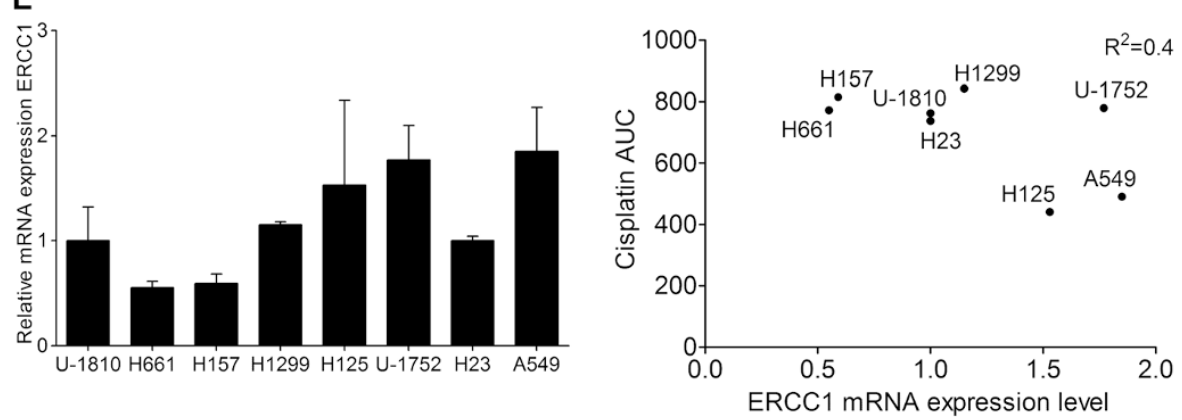

Fig. 4 In silico mapping of the DKK1 interactome using Ingenuity Pathway Analysis (IPA). a IPA-generated network built around DKK1 showing the direct upstream transcriptional regulators. Those that showed concurrent up-regulation along with DKK1 in replicate 1 are shown in grey. b IPA-generated network centered on DKK1 showing downstream signaling proteins that are indirectly regulated by DKK1. Those that were regulated also in replicate 1 are shown in grey. For $\mathbf{a}$ and $\mathbf{b}$, activation $(-)$, inhibition $(-)$ or reports on both $(-)$ ), indicates the regulation retrieved from Ingenuity. c Left panel: Q-RT-PCR showing the mRNA expression level of DKK1 in a panel of NSCLC cell lines. 18S rRNA was used as a loading control. Right panel: Correlation between baseline DKK1 mRNA expression and the cisplatin sensitivity of NSCLC cell lines after prolonged exposure (measured as area under the curve (AUC) in MTT assay after $72 \mathrm{~h}$ continuous treatment, based on three experiments each performed in triplicate). mRNA expression levels of RRM1 $\mathbf{d}$ and $E R C C 1 \mathbf{e}$ together with correlation to cisplatin sensitivity as described in $\mathbf{c}$ 


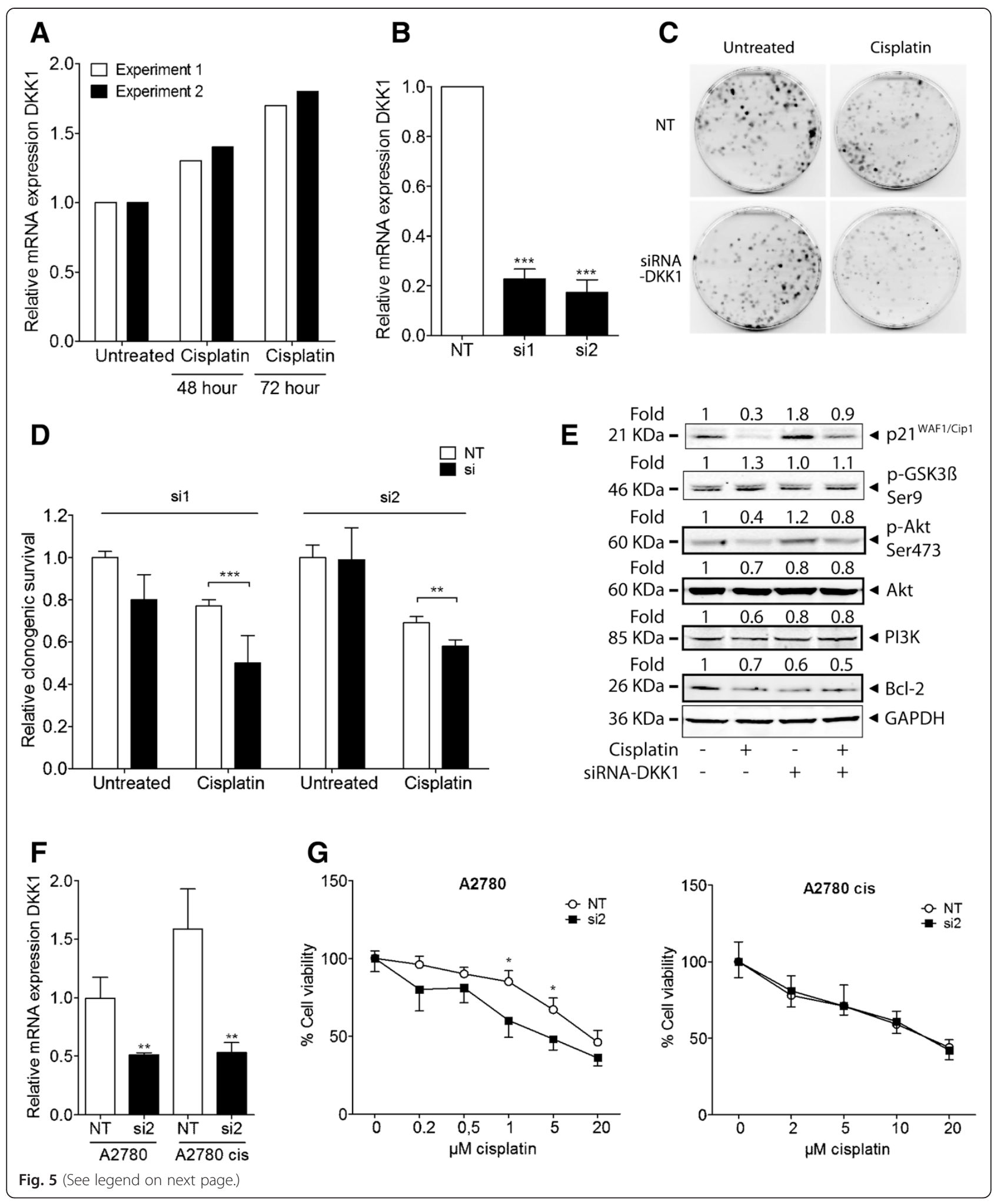


(See figure on previous page.)

Fig. 5 Knockdown of DKK1 sensitizes NSCLC cells to cisplatin. (a) Q-RT-PCR shows the relative mRNA expression of DKK1 48 and $72 \mathrm{~h}$ after a short pulse treatment of U-1810 cells with $10 \mu \mathrm{M}$ cisplatin ( $1 \mathrm{~h}$ ). The results of two separate experiments are shown. $\mathbf{b} \mathrm{U}-1810$ cells were transfected with non-targeting (NT) or DKK1-specific siRNAs (si1 or si2); silencing of DKK1 mRNA expression was confirmed by q-RT-PCR. 18S rRNA was used as a loading control. ${ }^{* * *} ; p<0.005$ vs NT control. c U-1810 cells were transfected with siRNA-DKK1 or NT siRNA and colony formation capacity was assayed 9 days after treatment or not with a short pulse of cisplatin $(1 \mathrm{~h}, 10 \mu \mathrm{M})$. Representative images of culture dishes for si1. $\mathbf{d}$ Clonogenic capacity relative to untreated, NT siRNA-transfected cells for U-1810 si1 and si2. ${ }^{* * *} ; p<0.005,{ }^{* *} ; p<0.01$, when comparing DKK1 siRNA-transfected to NT siRNA-transfected cells after cisplatin treatment. e Western blots showing p21 ${ }^{\text {WAF1/Cip1, }}$, phosphorylated GSK3B (Ser9) and AKT (Ser473), total AKT, PI3K and BCl-2 in U-1810 cells $24 \mathrm{~h}$ after treatment with cisplatin $(1 \mathrm{~h}, 10 \mu \mathrm{M})$, which was performed on reseeded cells after the $72 \mathrm{~h}$-transfection with NT control or siRNA-DKK1 (si1). GAPDH was used as a loading control. (f-g) A2780 and its cisplatin-resistant subtype A2780 cis cells were transfected with siRNA-DKK1 (si2) or NT. f siRNA silencing of DKK1 mRNA expression was confirmed by q-RT-PCR. ${ }^{* *} ; p<0.01$. $g$ Cell viability was assayed $72 \mathrm{~h}$ after continuous treatment with cisplatin, relative to untreated NT or si, using MTT assay. *; $p<0.05$

exposure led to a slightly (1.3-fold) increased $D K K 1$ mRNA expression at $48 \mathrm{~h}$ post treatment which was further increased to 1.7 -fold after $72 \mathrm{~h}$. This may suggest that cisplatin can elicit increased $D K K 1$ expression as a protective response. To explore if $D K K 1$ is of importance for cisplatin refractoriness, $D K K 1$ expression was ablated in NSCLC U-1810 and A549 cells using siRNA and the effect on clonogenic survival was examined. An 80-90 \% ablation of DKK1 mRNA expression was achieved after transfection with either of two different siRNA (si1 and si2) for $72 \mathrm{~h}$ as compared to the nontargeting control siRNA in both NSCLC cell lines (Fig. 5b and Additional file 3A). Notably, while cisplatin treatment or knockdown of DKK1 per se each reduced the colony formation capacity by up to $30 \%$, the combination of these treatments reduced colony formation by $50 \%$ in U-1810 cells, demonstrating that DKK1 ablation sensitizes these NSCLC cells to cisplatin (Fig. 5c-d). Moreover, the same cisplatin-sensitizing effect of DKK1 knockdown was also evident in A549 cells but at a slightly lower magnitude (Additional file 3B). In summary, these data indicate that knockdown of DKK1 confers long term cisplatin sensitization in NSCLC cells and results in reduced colony forming capacity.

The influence of $D K K 1$ ablation on two of its IPAsuggested indirect downstream targets i.e. p21 WAF1/ Cip1 $[22,23]$ and $G S K 3 B[28,29]$ was also examined in non-targeting or siDKK1-transfected U-1810, $24 \mathrm{~h}$ after treatment with cisplatin for $1 \mathrm{~h}$ (Fig. 5e). Knockdown of $D K K 1$ per se increased the expression of p21 ${ }^{\text {WAF1/Cip1 }}$ (Fig. 5e), implicating G1 arrest and possibly a senescent phenotype. In these p53-lacking U1810 cells [33], cisplatin generally reduced the $\mathrm{p} 21^{\text {WAF1/Cip1 }}$ levels (Fig. 5e), however when siDKK1 was applied the reduction was smaller and a higher p21 $1^{\text {WAF1/Cip1 }}$ expression level remained similar to untreated, non-targeting cells. This was supported in the p53 wild type A549 cells where cisplatin increased $\mathrm{p} 21^{\mathrm{WAF} 1 / \mathrm{Cip} 1}$, the increase is however more pronounced after siDKK1 and cisplatin than after cisplatin alone (Additional file 3C). The activity of GSK3B, which is decreased by phosphorylation at serine 9 , was however not significantly affected upon $D K K 1$ ablation or cisplatin treatment (Fig. 5e).

An increased activity of growth factor-regulated kinases and up-regulated expression of anti-apoptotic proteins are reported to contribute to a cisplatinrefractory phenotype and to hamper cisplatin response in solid tumor cells [4]. Phosphatidylinositol-3-kinase/vAkt murine thymoma viral oncogene homolog (PI3K/ AKT) signaling has been demonstrated to be increased in cisplatin-refractory ovarian and colon cancer cells [34-36]. Moreover, the activation of AKT by Ser473 phosphorylation is reported to in part impair cisplatin-induced apoptosis by inactivating $\mathrm{Bcl}$-2-associated death promoter (BAD) or by increasing B-cell lymphoma 2 (Bcl-2) expression levels, thereby blocking Bcl-2 homologous antagonist/ killer/Bcl-2-associated X protein (BAK/BAX) activation [37, 38]. Accordingly, we examined the phosphorylation of AKT (Ser473) and total AKT, PI3K and Bcl-2 expression levels in these siDKK1-transfected, cisplatin-treated U-1810 cells (Figure 5e).

The basal level of phospho-AKT (Ser 473) was slightly increased in DKK1-knocked cells, while cisplatin reduced the levels in both non-targeting and $D K K 1$ siRNA-transfected cells. Only minor decreases in total AKT and PI3K expression was seen after cisplatin and/or DKK1 siRNA (Fig. 5e). Our results suggest that although PI3K/AKT signaling might still be players in this context, they do not seem to play a prominent role in the increased cisplatin sensitivity of cells lacking DKK1. On the other hand, in both U-1810 and A549 cells, Bcl-2 displayed a reduced expression in DKK1-knocked cells compared to non-targeting, untreated cells (Fig. 5e, Additional file 3C). Similarly, cisplatin caused a reduced expression of $\mathrm{Bcl}-2$ and when DKK1 siRNA and cisplatin were combined, downregulation was clearly evident. The expression of another Bcl-2 family member, B-cell lymphoma-extra large (Bcl-xL), was not altered in these samples (data not shown). Albeit further studies on the role of apoptotic signaling in DKK1 siRNA-mediated signaling to cisplatin is needed, this data suggests that $D K K 1$ ablation may sensitize for cisplatin by down-regulating Bcl-2 expression. 


\section{DKK1 knockdown sensitizes ovarian cancer cells to cisplatin}

To validate our results from NSCLC in another tumor type, we tested the ovarian cancer cell lines A2780 and A2780 cis. A2780 cis is a subline of A2780 that developed acquired cisplatin resistance after exposure to increasing concentrations of cisplatin over time [39]. Hence A2780 cis is about 7-fold more resistant to cisplatin than its parental A2780. When applying DKK1 siRNA (si2), DKK1 mRNA expression was down to about $50 \%$ in the parental A2780 cell line and to approximately $30 \%$ in A2780 cis versus their respective non-targeting control (Fig. 5f). When assaying DKK1 mRNA levels, a higher basal level (1.6-fold) was found in A2780 cis as compared to A2780 cells (Fig. 5f). siDKK1 significantly sensitized the A2780, but not the A2780 cis cells, to cisplatin treatment (Fig. 5g). In summary, these data indicate that knockdown of DKK1 also can sensitize cells of other tumor types than NSCLC to cisplatin. The acquired resistance of A2780 cis was however more difficult to target and not possible to revert at the level of DKK1 knockdown achieved in these experiments. Nevertheless, A2780 cis had a higher baseline DKK1 expression level which fits with our data of an involvement of DKK1 in cisplatin resistance.

\section{Discussion}

Platinum-based compounds e.g. cisplatin and carboplatin constitute the standard chemotherapy regimen for NSCLC. Unfortunately a large proportion of the cases display intrinsic resistance to these platinum drugs and for yet another fraction, a platinum-refractory phenotype typically develops during the treatment course [40]. In this study, we aimed to identify molecular determinants which drives a cisplatin-refractory phenotype and hence could be used either as biomarkers of response or as sensitizing targets for cisplatin in NSCLC. Our approach of studying gene expression alterations in cisplatinsurviving NSCLC clones is different from previous reports using either very high, non-clinically achievable cisplatin doses in short term treatment schedules [41] or tumor cell models of acquired resistance [42]. The latter is mostly reported to result in resistance mechanisms involving up-regulation of membrane-associated drug efflux pumps such as ATP-binding cassette proteins and copper-extruding P-type ATPases [4, 8].

In our three biological replicates only FMN1 showed altered expression in all three replicates, illustrating that NSCLC cells surviving cisplatin pulse treatment have heterogeneous clonogenic survival capacity and gene expression patterns. A possible reason may be that few prominent long term effects are seen on the RNA level 9 days after cisplatin treatment. However, one interpretation of this outcome is that cisplatin treatment can result in the expansion of different resistant clones in different experiments. This clonal evolution hypothesis has been demonstrated after epidermal growth factor receptor (EGFR)-ablative therapy, where a very low number of Kirsten rat sarcoma viral oncogene homolog (KRAS)-mutated colorectal cancer cells emerged to become the dominant clone among the surviving cells [43, 44 . Hence, we speculate that even small initial variations in cisplatin responsiveness can induce certain clones to become dominant. Optimally, if not limited by the minimal amounts needed for the analysis method, it would be interesting to analyze multiples of clones separately to explore their differences and heterogeneity further.

We and others have shown that a chemotherapyrefractory cancer stem cell phenotype is evident in certain NSCLC cell lines $[14,45]$. However, this sphereforming capacity after enrichment in stem cell media was not found in the NSCLC cell line used in this study U-1810, suggesting that they might not contain an appreciable proportion of stem-like cells and that the heterogenic response of chemotherapy in this particular cell line likely is governed by other signaling cascades. We observed the same cisplatin response in clonogenic and MTT assays upon retreatment (Additional file 4), therefore we could verify that using our singletreatment setup, we were most likely only studying the primary effects in the surviving clones that were selected due to intrinsic refractoriness.

The one gene that was down-regulated in all three biological replicates was formin 1 (FMN1), a protein which enhances formation of cell-cell adhesion [16]. As cisplatin disrupts cell-cell adhesion before it induces apoptosis [46], one may speculate that the fraction of cells with low FMN1 expression may be less responsive to the adhesion-disruptive effects of cisplatin, and consequently survive. However, by overexpressing FMN1 we were not able to sensitize NSCLC cells to cisplatin indicating that either FMN1 is not directly involved in regulating cisplatin sensitivity or it acts in concert with other signaling aberrations to confer survival advantage if down-regulated, which not is recapitulated when forced overexpression is used.

Analysis of each individual experiment revealed $D K K 1, X R C C 2$ and $L G A L S 9$ as top scored differentially up-regulated genes in cisplatin-surviving clones from replicates 1 and 3 , respectively. It is well documented that cisplatin treatment activates multiple DNA damage signaling cascades, and here we found an increased expression of XRCC2, a member of the homologous recombination repair pathway, in cisplatinrefractory residual NSCLC clones. This up-regulation might be due to inherent properties of the cells, or alternatively, a selective pressure on the surviving clones to up-regulate proteins involved in DNA repair to withstand the damage. In line with our data, mouse embryonic 
fibroblasts deficient in $X R C C 2$ are reported to be hypersensitive to cisplatin treatment [47], further pointing towards a connection between high XRCC2 expression levels and cisplatin resistance. Albeit LGALS9 has not yet been implicated in NSCLC or in a chemotherapy-refractory phenotype of other tumor cells, various galectins such as galectin- 1 and -3 were reported to have a role in driving a chemotherapyrefractory phenotype $[48,49]$.

Importantly, we demonstrate that $D K K 1$ has a role in the intrinsic platinum responsiveness of NSCLC, as siRNA-mediated ablation of DKK1 sensitized NSCLC cells to cisplatin and reduced their clonogenic survival potential. DKK1 is a secreted protein with dual antiand pro-survival functions in different tumor types. For instance, DKK1 may act as a tumor suppressor through inhibition of $\mathrm{Wnt} / \beta$-catenin signaling and is reported to activate apoptosis in multiple tumor types e.g breast cancer, renal cell carcinoma, melanoma and choriocarcinoma [50-53]. In head and neck cancer cells, decreased DKK1 expression was associated with acquired cisplatin resistance [42], whereas overexpression of $D K K 1$ in a glioma cell line sensitized these cells to DNA damaging agents including cisplatin [54]. Some of these data are opposed to our study in which DKK1 was upregulated in cisplatin-surviving NSCLC clones and its knockdown conferred cisplatin sensitivity. These differences could possibly be attributed to tumor type specific divergences in signaling cascades, or in mechanisms of acquired cisplatin resistance. Our results of cisplatin sensitization from NSCLC were however validated also in ovarian cancer cells which were sensitized to cisplatin upon siRNA knockdown of DKK1. Yet we could not sensitize the acquired cisplatin-resistant subclone A2780 cis at the level of knockdown achieved in our experiments. Our interpretation is that DKK1 regulates intrinsic cisplatin resistance, still it may not be the main driver of acquired cisplatin resistance.

Multiple studies have demonstrated an oncogenic role of $D K K 1$ in diverse tumor types such as multiple myeloma, hepatoblastoma, Wilm's tumor and hormoneresistant breast cancer [55-57]. Moreover, high serum level of DKK1 has been detected in patients with NSCLC and esophageal carcinoma where it was associated with tumor progression and poor outcome of these malignancies suggesting that $D K K 1$ in these tumor malignancies may have an oncogenic role $[18,20,58]$. Using the cBioPortal for Cancer Genomics (cbioportal.org) [59, 60] which integrates data from several databases including The Cancer Genome Atlas, we found that DKK1 was altered at the level of either mRNA upregulation, mutation, homozygous deletion or amplification in a total of 6-9 \% of lung adeno- or squamous cell carcinoma patients $[61,62]$. In the adenocarcinoma population, the mentioned alterations in DKK1 were also linked to a significantly reduced overall survival [62], further supporting the importance of DKK1 in NSCLC. Yet it remains to be demonstrated if DKK1 regulate intrinsic cisplatin sensitivity in vivo. Such studies could be performed using NSCLC patient-derived xenografts in mice. To demonstrate that DKK1 is a predictor of cisplatin refractoriness in vivo in NSCLC patients is more challenging as it would require a biopsy of primary tumor and metastasis prior and post cisplatin treatment which is not a standard routine in our clinic at present. Hence a controlled clinical trial would be required in order to adequately address this issue.

Through bioinformatics analysis of $D K K 1$, we identified a number of putative transcription regulators of this gene. Specifically, ectopic expression of the Wnt signaling components TCF4 as well as active $\beta$-catenin induce transcription of the $D K K 1$ gene, and the $D K K 1$ promoter contains several TCF4 response elements, which fits well with our data of co-regulated TCF4 and DKK1 [63]. $D N A J B 6$ is known to activate $D K K 1$ expression and also had an increased expression in our data demonstrating a regulation which fits earlier reported alterations [64]. In contrast, EZH2 and $H D A C 2$ which cause repression of $D K K 1$ according to literature [65-67], also showed increased expression in our data. However, at least the $H D A C 2$ effects were reported to be p53-dependent [67] and might therefore not apply in this cell system since U-1810 cells lack p53 expression due to a truncating mutation at p53 codon 172 [33]. Nevertheless, additional validation experiments using siRNA/overexpression of these proteins are needed to confirm a role for these transcriptional regulators in the observed increased DKK1 expression in the cisplatin-refractory NSCLC clones.

IPA analysis identified $\mathrm{p} 21^{\mathrm{WAF} 1 / \mathrm{Cip} 1}$ to be a putative downstream effector protein of DKK1, and p21 WAF1/Cip1 is reported to negatively regulate the cell cycle, i.e. to have a tumor suppressor role [68]. In rat mesenchymal stem cells, addition of recombinant DKK1 protein decreased $\mathrm{p} 21^{\mathrm{WAF} 1 / \mathrm{Cip} 1}$ mRNA levels as well as the $\beta$-gal staining, both indicators of senescence [23]. This is in line with our data where DKK1 knockdown increased p21 WAF1/Cip1 . Another IPA-retrieved report show however that transgenic mice with ectopic expression of DKK1 in intestinal crypts has an up-regulated p21 WAF1/ Cip1, possibly as a consequence of repression of c-myc expression [22]. Overexpression or silencing of $p 21^{\text {WAF1/ }}$ ${ }^{C i p 1}$ induced or reduced, respectively, the cytotoxicity of cisplatin in NSCLC A549 cells, signifying its importance in cisplatin response in NSCLC [69]. After cisplatin treatment, an increased expression of $\mathrm{p} 21^{\mathrm{WAF} 1 / \mathrm{Cip} 1}$ is commonly seen in p53 wild type cell lines [70], like we see in A549 cells (Additional file 3C). Although $\mathrm{p} 21^{\mathrm{WAF} 1 / \mathrm{Cip} 1}$ was decreased in the p53-mutant U-1810 
cells after cisplatin, the level was higher after siDKK1 combined with cisplatin. Data from A549 cells support this elevated $\mathrm{p} 21^{\mathrm{WAF} 1 / \mathrm{Cip} 1}$ level in siDKK1-ablated, cisplatin-treated samples, despite their differential response to cisplatin. Therefore we speculate that $\mathrm{p} 21^{\mathrm{WAF} 1 / \mathrm{Cip} 1}$ could contribute to the reduced growth after DKK1 knockdown and cisplatin by induction of G1 arrest and senescence.

GSK3B is a negative regulator of Wnt signaling pathway and inhibition of GSK3B activity, i.e. increased p-Ser9, has previously been shown to confer resistance to cisplatin in lung and ovarian cancer cells $[29,71,72]$. The mRNA expression was co-regulated with DKK1 in the cisplatinrefractory cells but we did not see any change in the phospho-GSK3B at the time point studied after siDKK1. Still, the previously reported $D K K 1$-regulation (Fig. 4b) of both GSK3B (up) and DLG4 (down) was confirmed in replicate 1 .

No major changes were seen when we analyzed the PI3K/AKT proteins which are known to be involved in cisplatin-refractoriness [35]. We did however see an almost 2-fold down-regulation in expression of the anti-apoptotic protein Bcl-2 in both DKK1 siRNA and DKK-1 ablated and cisplatin-treated samples in both U1810 and A549 cells (Fig. 5e and Additional file 3C). A reduced Bcl-2 allows for activation of pro-apoptotic BAK/ $\mathrm{BAX}$, which is required for proper cisplatin response [37], i.e. increased cisplatin-induced apoptosis. This could serve as a mechanism for the sensitization since elevated levels of Bcl-2 and other proteins within the same family e.g. BCL-XL and MCL1 correlate with cisplatin resistance as well as tumor recurrence in NSCLC and other cancers [73-76]. Small molecule inhibitors for Bcl-2-like proteins are also tested in clinical trials together with cisplatin [77]. Yet the importance of this down-regulation and the role of DKK1 in regulating cisplatin-induced apoptotic signaling would require further studies.

Apart from DKK1's role as a Wnt-signaling antagonist, DKK1 overexpression correlates to an accumulation of $\beta$-catenin in the cytoplasm or nucleus in clinical samples from hepatocellular carcinoma [78]. We analyzed the total level of $\beta$-catenin protein (data not shown) in the samples from Fig. 5e but did however not detect any differences at this time point.

\section{Conclusions}

Overall, we show here that NSCLC cells surviving a short cisplatin pulse treatment have heterogeneous gene expression patterns. We identify a number of genes as potential markers of intrinsic cisplatin refractoriness, such as DKK1, FMN1, XRCC2 and LGALS9. Moreover, we demonstrate that $D K K 1$ is a possible target that can be used for cisplatin sensitizing purposes in NSCLC cells and likely also other tumor types such as ovarian carcinoma. Our study therefore emphasize that further studies should be performed with respect to $D K K 1$ and its interactome to reveal how it can be used to sensitize NSCLC to platinum-based therapy, especially in an in vivo setting such as NSCLC patient-derived xenografts.

\section{Availability of supporting data}

The data set supporting the results of this article is available in NCBI's Gene Expression Omnibus [11] repository and accessible through GEO Series accession number GSE48244 [http://www.ncbi.nlm.nih.gov/geo/ query/acc.cgi?acc $=$ GSE48244].

\section{Additional files}

\section{Additional file 1: Hierarchical clustering was performed using} Partek Genomics Suite v6.6. Fold changes for genes in cisplatin-surviving compared to untreated U-1810 cells for the replicates R1, R2 and R3 were used, where red designates upregulated and blue downregulated genes. All genes which were up- or down-regulated over 1.5-fold in any replicate were included (for those regulated in more than one replicate, the additional redundant ones were removed). (TIFF $1678 \mathrm{~kb}$ )

Additional file 2: A plasmid carrying FMN1 was transfected into NSCLC U-1810 cells for $\mathbf{2 4}$ h, for which Lipofectamine-only served as control. After another $24 \mathrm{~h}$ cells were tested for FMN1 expression by western blot (A) or subjected to cisplatin treatment for $72 \mathrm{~h}$ after which cell viability was examined by MTT (B). (A) Representative blot for FMN1 expression in which $\beta$-tubulin served as loading control. (B) Cell survival after FMN1 overexpression in U-1810 cells, given relative to Lipofectamine-treated cells. Data shown is the mean \pm SEM of three experiments. (TIFF $120 \mathrm{~kb}$ )

Additional file 3: A549 cells were transfected with non-targeting (NT) or DKK1-specific siRNA (si1). (A) Silencing of DKK1 mRNA expression was confirmed by q-RT-PCR. 18S rRNA was used as a loading control. ***; $p<0.005$ vs NT control. (B) A549 cells were transfected with siRNA-DKK1 or NT siRNA and colony formation capacity was assayed 9 days after treatment or not with a short pulse of cisplatin $(1 \mathrm{~h}, 10 \mu \mathrm{M})$. Clonogenic capacity relative to untreated, NT siRNA-transfected cells, *; $p<0.05$ (C) Western blots showing p21WAF1/Cip1 and BCl-2 in A549 cells $24 \mathrm{~h}$ after treatment with cisplatin $(1 \mathrm{~h}, 10 \mu \mathrm{M})$, which was performed on reseeded cells after the $72 \mathrm{~h}$-transfection with non-targeting control or siRNA-DKK1 (si1). GAPDH was used as a loading control. (TIFF $423 \mathrm{~kb}$ )

Additional file 4: Retreatment of the pooled surviving U-1810-clones from a first round of clonogenic survival, where the first treatment is indicated for cisplatin-surviving (10 $\mu \mathrm{M}$, Cisplatin as $1 \mathrm{st})$ or untreated (Untreated as 1st) clones. (A) The relative clonogenic survival in the first (1st) round is depicted in the first white bar, the grey bars are data from the retreated (2nd) experiment as described above, also using $10 \mu \mathrm{M}$ cisplatin. (B) MTT cell viability data. Doses used for the retreatment were from $0.5-50 \mu \mathrm{M}$ cisplatin and viability was analyzed after $72 \mathrm{~h}$. Average \pm SD from three experiments, MTT was performed in triplicate. (TIFF 54 kb)

\section{Abbreviations}

AKT: $v$-Akt murine thymoma viral oncogene homolog; AUC: area under the curve; BAD: $\mathrm{BCl}$-2-associated death promoter; BAK: $\mathrm{BCl}-2$ homologous antagonist/killer; BAX: Bcl-2-associated X protein; Bcl-2: B-cell lymphoma 2; BCl-xL: B-cell lymphoma-extra large; CDKN1A: cyclin-dependent kinase inhibitor 1A; DKK1: Dickkopf WNT signaling pathway inhibitor 1; DLG4: disks large homolog 4; DNAJB6: DnaJ homolog subfamily B member 6; EGFR: epidermal growth factor receptor; EPHB2: ephrin type-B receptor 2; ERCC1: excision repair cross-complementing rodent repair deficiency, complementation group 1; EZH2: enhancer of zeste homolog 2; FMN1: formin 1; GEO: Gene Expression Omnibus; GSK3B: glycogen synthase kinase 3 beta; HDAC2: histone deacetylase 2; ICL: inter-strand crosslink; IPA: Ingenuity Pathway Analysis tool; KRAS: Kirsten rat sarcoma viral oncogene homolog; LC: lung cancer; LGALS9: lectin, 
galactoside-binding, soluble 9; MAPK1: mitogen activated protein kinase 1; MAPT: microtubule-associated protein tau; MTT: 3-[4,5-dimethylthiazol-2-yl]-2,5-

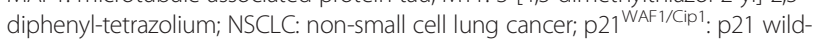
type activating fragment-1/cyclin-dependent kinase inhibitory protein-1; PI3K: phosphatidylinositol-3-kinase; PLIER: probe logarithmic intensity error estimation; PM GCBG: perfect match GC composition-based background correction; q-RT-PCR: quantitative real time polymerase chain reaction; RRM1: ribonucleotide reductase M1; SCLC: small cell lung cancer; SNORD: small nucleolar RNAs; TCF4: transcription factor 4; XRCC2: X-ray repair cross-complementing protein 2 .

\section{Competing interests}

The authors declare that they have no competing interests.

\section{Authors' contributions}

$R L, L L, K V, P H$, and DZ designed the study. $H S, L L, D Z$ and $B M$ performed the experiments. $\mathrm{HS}$ and $\mathrm{LL}$ summarized the data and drafted the manuscript $\mathrm{PH}, \mathrm{LL}, \mathrm{MN}$ and $\mathrm{KV}$ designed the revision experiments and $\mathrm{MN}$ and $\mathrm{LL}$ conducted these experiments with $\mathrm{PH} / \mathrm{KV}$ helping out in their evaluation. All authors gave input to the manuscript and contributed to the discussion/ conclusions of the study.

\section{Acknowledgements}

This research was supported by grants from the Swedish Cancer Society (grant agreement 120761/2012), the Cancer Society in Stockholm (to RL, KV and PH), the Swedish Research Council (to RL, grant agreement 90266701/ 2009), The Swedish National Board of Health and Welfare, the Stockholm County Council, Karolinska Institutet research funds and the European Union (FP6 Chemores, grant agreement 037669 and FP7 APO-SYS, grant agreement 200767). The financial support (to HS) from the Ministry of Higher Education and Scientific Research in Iraqi-Kurdistan Regional Government and from the Swedish Cancer Society (to LL) as a post-doctoral grant for lung cancer research are greatly appreciated.

\section{Received: 2 September 2014 Accepted: 1 September 2015 Published online: 09 September 2015}

\section{References}

1. Cagle PT, Allen TC. Lung cancer genotype-based therapy and predictive biomarkers: present and future. Arch Pathol Lab Med. 2012;136(12):1482-91.

2. Yeung $K$, Carlson JJ. Clinical and economic review of erlotinib in non-small-cell lung cancer. Expert Rev Pharmacoecon Outcomes Res. 2012;12(4):411-23.

3. Shen DW, Pouliot LM, Hall MD, Gottesman MM. Cisplatin resistance: a cellular self-defense mechanism resulting from multiple epigenetic and genetic changes. Pharmacol Rev. 2012;64(3):706-21.

4. Galluzzi L, Senovilla L, Vitale I, Michels J, Martins I, Kepp O, et al. Molecular mechanisms of cisplatin resistance. Oncogene. 2012;31(15):1869-83.

5. Olaussen KA, Dunant A, Fouret P, Brambilla E, Andre F, Haddad V, et al. DNA repair by ERCC1 in non-small-cell lung cancer and cisplatin-based adjuvant chemotherapy. N Engl J Med. 2006:355(10):983-91.

6. Rosell R, Danenberg KD, Alberola V, Bepler G, Sanchez JJ, Camps C, et al. Ribonucleotide reductase messenger RNA expression and survival in gemcitabine/cisplatin-treated advanced non-small cell lung cancer patients. Clin Cancer Res. 2004:10(4):1318-25

7. Mohammed Ael S, Eguchi H, Wada S, Koyama N, Shimizu M, Otani K, et al. TMEM158 and FBLP1 as novel marker genes of cisplatin sensitivity in non-small cell lung cancer cells. Exp Lung Res. 2012;38(9-10):463-74.

8. Oiso S, Takayama Y, Nakazaki R, Matsunaga N, Motooka C, Yamamura A, Ikeda R, Nakamura K, Takeda Y, Kariyazono H: Factors involved in the cisplatin resistance of KCP4 human epidermoid carcinoma cells. Oncol Rep. 2014;31(2):719-26.

9. Bergh J, Nilsson K, Ekman R, Giovanella B. Establishment and characterization of cell lines from human small cell and large cell carcinomas of the lung. Acta Pathol Microbiol Immunol Scand A. 1985;93(3):133-47.

10. Rio DC, Ares Jr M, Hannon GJ, Nilsen TW. Purification of RNA using TRIzol (TRI reagent). Cold Spring Harb Protoc. 2010;2010:6. pdb prot5439.

11. Edgar R, Domrachev M, Lash AE. Gene Expression Omnibus: NCBI gene expression and hybridization array data repository. Nucleic Acids Res. 2002;30(1):207-10
12. Salim H, Arvanitis A, de Petris L, Kanter L, Haag P, Zovko A, et al. miRNA-214 is related to invasiveness of human non-small cell lung cancer and directly regulates alpha protein kinase 2 expression. Genes Chromosomes Cancer. 2013:52(10):895-911.

13. Livak KJ, Schmittgen TD. Analysis of relative gene expression data using real-time quantitative PCR and the 2(-Delta Delta C(T)) Method. Methods. 2001;25(4):402-8.

14. Lundholm L, Haag P, Zong D, Juntti T, Mork B, Lewensohn R, et al. Resistance to DNA-damaging treatment in non-small cell lung cancer tumor-initiating cells involves reduced DNA-PKNATM activation and diminished cell cycle arrest. Cell Death Dis. 2013;4:e478.

15. Goodisman J, Souid AK. Constancy in integrated cisplatin plasma concentrations among pediatric patients. J Clin Pharmacol. 2006:46(4):443-8.

16. Dettenhofer M, Zhou F, Leder P. Formin 1-isoform IV deficient cells exhibit defects in cell spreading and focal adhesion formation. PLoS One. 2008;3(6):e2497.

17. Cedeno-Laurent F, Dimitroff CJ. Galectins and their ligands: negative regulators of anti-tumor immunity. Glycoconj J. 2012;29(8-9):619-25.

18. Sato N, Yamabuki T, Takano A, Koinuma J, Aragaki M, Masuda K, et al. Wnt inhibitor Dickkopf-1 as a target for passive cancer immunotherapy. Cancer Res. 2010;70(13):5326-36.

19. Yonetani $Y$, Hochegger H, Sonoda E, Shinya S, Yoshikawa H, Takeda S, et al. Differential and collaborative actions of Rad51 paralog proteins in cellular response to DNA damage. Nucleic Acids Res. 2005;33(14):4544-52

20. Yamabuki T, Takano A, Hayama S, Ishikawa N, Kato T, Miyamoto M, et al. Dikkopf-1 as a novel serologic and prognostic biomarker for lung and esophageal carcinomas. Cancer Res. 2007:67(6):2517-25.

21. Li S, Qin X, Guo X, Cui A, He Y, Wei S, et al. Dickkopf-1 is oncogenic and involved in invasive growth in non small cell lung cancer. PLoS One. 2013;8(12):e84944.

22. Pinto D, Gregorieff A, Begthel $H$, Clevers $H$. Canonical Wnt signals are essential for homeostasis of the intestinal epithelium. Genes Dev. 2003;17(14):1709-13.

23. Zhang DY, Wang HJ, Tan YZ. Wnt/b-Catenin Signaling Induces the Aging of Mesenchymal Stem Cells through the DNA Damage Response and the p53/p21 Pathway. PLoS One. 2011;6(6):e21397.

24. Caricasole A, Copani A, Caraci F, Aronica E, Rozemuller AJ, Caruso A, et al. Induction of Dickkopf-1, a negative modulator of the Wnt pathway, is associated with neuronal degeneration in Alzheimer's brain. J Neurosci. 2004:24(26):6021-7.

25. Salcedo-Tello P, Hernandez-Ortega K, Arias C. Susceptibility to GSK3beta-induced tau phosphorylation differs between the young and aged hippocampus after Wnt signaling inhibition. J Alzheimers Dis. 2014;39(4):775-85.

26. Zhang QG, Wang R, Khan M, Mahesh V, Brann DW. Role of Dickkopf-1, an antagonist of the Wnt/beta-catenin signaling pathway, in estrogen-induced neuroprotection and attenuation of tau phosphorylation. J Neurosci. 2008:28(34):8430-41.

27. Gortazar AR, Martin-Millan M, Bravo B, Plotkin LI, Bellido T. Crosstalk between caveolin-1/extracellular signal-regulated kinase (ERK) and beta-catenin survival pathways in osteocyte mechanotransduction. J Biol Chem. 2013;288(12):8168-75

28. Fortress AM, Schram SL, Tuscher JJ, Frick KM. Canonical Wnt signaling is necessary for object recognition memory consolidation. J Neurosci. 2013;33(31):12619-26.

29. Guo AJ, Choi RC, Cheung AW, Chen VP, Xu SL, Dong TT, et al. Baicalin, a flavone, induces the differentiation of cultured osteoblasts: an action via the Wnt/beta-catenin signaling pathway. J Biol Chem. 2011:286(32):27882-93

30. Kuhnert F, Davis CR, Wang HT, Chu P, Lee M, Yuan J, et al. Essential requirement for Wnt signaling in proliferation of adult small intestine and colon revealed by adenoviral expression of Dickkopf-1. Proc Natl Acad Sci U S A. 2004;101(1):266-71.

31. Gillespie JR, Bush JR, Bell Gl, Aubrey LA, Dupuis H, Ferron M, et al. GSK-3beta function in bone regulates skeletal development, whole-body metabolism, and male life span. Endocrinology. 2013;154(10):3702-18.

32. Roberts S, Delury C, Marsh E. The PDZ protein discs-large (DLG): the 'Jekyll and Hyde' of the epithelial polarity proteins. FEBS J. 2012;279(19):3549-58. 
33. Sirzen F, Zhivotovsky B, Nilsson A, Bergh J, Lewensohn R. Spontaneous and radiation-induced apoptosis in lung carcinoma cells with different intrinsic radiosensitivities. Anticancer Res. 1998;18(2A):695-9.

34. Altomare DA, Wang HQ, Skele KL, De Rienzo A, Klein-Szanto AJ, Godwin AK, et al. AKT and mTOR phosphorylation is frequently detected in ovarian cancer and can be targeted to disrupt ovarian tumor cell growth. Oncogene. 2004;23(34):5853-7.

35. Yang X, Fraser M, Moll UM, Basak A, Tsang BK. Akt-mediated cisplatin resistance in ovarian cancer: modulation of p53 action on caspasedependent mitochondrial death pathway. Cancer Res. 2006;66(6):3126-36.

36. Zhang J, Zhang LL, Shen L, Xu XM, Yu HG. Regulation of AKT gene expression by cisplatin. Oncol Lett. 2013;5(3):756-60.

37. Czabotar PE, Lessene G, Strasser A, Adams JM. Control of apoptosis by the $\mathrm{BCl}-2$ protein family: implications for physiology and therapy. Nat Rev Mol Cell Biol. 2014;15(1):49-63.

38. Fulda S. Modulation of mitochondrial apoptosis by PI3K inhibitors. Mitochondrion. 2013;13(3):195-8.

39. Behrens BC, Hamilton TC, Masuda H, Grotzinger KR, Whang-Peng J, Louie $\mathrm{KG}$, et al. Characterization of a cis-diamminedichloroplatinum(II)-resistant human ovarian cancer cell line and its use in evaluation of platinum analogues. Cancer Res. 1987;47(2):414-8.

40. Chang A. Chemotherapy, chemoresistance and the changing treatment landscape for NSCLC. Lung Cancer. 2011;71(1):3-10.

41. Galluzzi L, Morselli E, Vitale I, Kepp O, Senovilla L, Criollo A, et al. miR-181a and miR-630 regulate cisplatin-induced cancer cell death. Cancer Res. 2010;70(5):1793-803.

42. Gosepath EM, Eckstein N, Hamacher A, Servan K, von Jonquieres G, Lage H, et al. Acquired cisplatin resistance in the head-neck cancer cell line Cal27 is associated with decreased DKK1 expression and can partially be reversed by overexpression of DKK1. Int J Cancer. 2008;123(9):2013-9.

43. Misale S, Yaeger R, Hobor S, Scala E, Janakiraman M, Liska D, et al. Emergence of KRAS mutations and acquired resistance to anti-EGFR therapy in colorectal cancer. Nature. 2012;486(7404):532-6.

44. Diaz Jr LA, Williams RT, Wu J, Kinde I, Hecht JR, Berlin J, et al. The molecular evolution of acquired resistance to targeted EGFR blockade in colorectal cancers. Nature. 2012;486(7404):537-40.

45. Eramo A, Lotti F, Sette G, Pilozzi E, Biffoni M, Di Virgilio A, et al. Identification and expansion of the tumorigenic lung cancer stem cell population. Cell Death Differ. 2008;15(3):504-14.

46. Imamdi R, de Graauw M, van de Water B. Protein kinase C mediates cisplatin-induced loss of adherens junctions followed by apoptosis of renal proximal tubular epithelial cells. J Pharmacol Exp Ther. 2004;311(3):892-903.

47. Tsaryk R, Fabian K, Thacker J, Kaina B. Xrcc2 deficiency sensitizes cells to apoptosis by MNNG and the alkylating anticancer drugs temozolomide, fotemustine and mafosfamide. Cancer Lett. 2006;239(2):305-13.

48. Chung LY, Tang SJ, Sun GH, Chou TY, Yeh TS, Yu SL, et al. Galectin-1 promotes lung cancer progression and chemoresistance by upregulating p38 MAPK, ERK, and cyclooxygenase-2. Clin Cancer Res. 2012;18(15):4037-47.

49. Kobayashi T, Shimura T, Yajima T, Kubo N, Araki K, Wada W, et al. Transient silencing of galectin-3 expression promotes both in vitro and in vivo drug-induced apoptosis of human pancreatic carcinoma cells. Clin Exp Metastasis. 2011;28(4):367-76.

50. Qiao L, Xu ZL, Zhao TJ, Ye LH, Zhang XD. Dkk-1 secreted by mesenchymal stem cells inhibits growth of breast cancer cells via depression of Wnt signalling. Cancer Lett. 2008;269(1):67-77.

51. Hirata H, Hinoda Y, Nakajima K, Kawamoto K, Kikuno N, Ueno K, et al. Wnt antagonist DKK1 acts as a tumor suppressor gene that induces apoptosis and inhibits proliferation in human renal cell carcinoma. Int J Cancer. 2011;128(8):1793-803.

52. Liu S, Howell P, Ren S, Fodstad O, Zhang G, Samant R, et al. Expression and functional analysis of the WAP four disulfide core domain 1 gene in human melanoma. Clin Exp Metastasis. 2009;26(7):739-49.

53. Peng S, Miao C, Li J, Fan X, Cao Y, Duan E. Dickkopf-1 induced apoptosis in human placental choriocarcinoma is independent of canonical Wnt signaling. Biochem Biophys Res Commun. 2006;350(3):641-7.

54. Shou J, Ali-Osman F, Multani AS, Pathak S, Fedi P, Srivenugopal KS. Human Dkk-1, a gene encoding a Wnt antagonist, responds to DNA damage and its overexpression sensitizes brain tumor cells to apoptosis following alkylation damage of DNA. Oncogene.

2002;21(6):878-89.
55. Tian E, Zhan F, Walker R, Rasmussen E, Ma Y, Barlogie B, et al. The role of the Wnt-signaling antagonist DKK1 in the development of osteolytic lesions in multiple myeloma. N Engl J Med. 2003;349(26):2483-94.

56. Wirths O, Waha A, Weggen S, Schirmacher P, Kuhne T, Goodyer CG, et al. Overexpression of human Dickkopf-1, an antagonist of wingless/WNT signaling, in human hepatoblastomas and Wilms' tumors. Lab Invest. 2003;83(3):429-34.

57. Forget MA, Turcotte S, Beauseigle D, Godin-Ethier J, Pelletier S, Martin J, et al. The Wnt pathway regulator DKK1 is preferentially expressed in hormone-resistant breast tumours and in some common cancer types. $\mathrm{Br} J$ Cancer. 2007;96(4):646-53.

58. Na Y, Lee SM, Kim DS, Park JY. Promoter methylation of Wht antagonist DKK1 gene and prognostic value in Korean patients with non-small cell lung cancers. Cancer Biomark. 2012;12(2):73-9.

59. Cerami E, Gao J, Dogrusoz U, Gross BE, Sumer SO, Aksoy BA, et al. The cBio cancer genomics portal: an open platform for exploring multidimensional cancer genomics data. Cancer Discov. 2012;2(5):401-4.

60. Gao J, Aksoy BA, Dogrusoz U, Dresdner G, Gross B, Sumer SO, et al. Integrative analysis of complex cancer genomics and clinical profiles using the cBioPortal. Sci Signal. 2013;6(269):11.

61. Cancer Genome Atlas Research Network. Comprehensive genomic characterization of squamous cell lung cancers. Nature. 2012;489(7417):519-25.

62. Cancer Genome Atlas Research Network. Comprehensive molecular profiling of lung adenocarcinoma. Nature. 2014;511(7511):543-50.

63. Gonzalez-Sancho JM, Aguilera O, Garcia JM, Pendas-Franco N, Pena C, Cal S, et al. The Wnt antagonist DICKKOPF-1 gene is a downstream target of beta-catenin/TCF and is downregulated in human colon cancer. Oncogene. 2005;24(6):1098-103.

64. Mitra A, Menezes ME, Shevde LA, Samant RS. DNAJB6 induces degradation of beta-catenin and causes partial reversal of mesenchymal phenotype. J Biol Chem. 2010;285(32):24686-94.

65. Cheng AS, Lau SS, Chen Y, Kondo Y, Li MS, Feng H, et al. EZH2-mediated concordant repression of Wnt antagonists promotes beta-catenin-dependent hepatocarcinogenesis. Cancer Res. 2011;71(11):4028-39.

66. Hussain M, Rao M, Humphries AE, Hong JA, Liu F, Yang M, et al. Tobacco smoke induces polycomb-mediated repression of Dickkopf-1 in lung cancer cells. Cancer Res. 2009;69(8):3570-8.

67. Harms $\mathrm{KL}$, Chen X. Histone deacetylase 2 modulates p53 transcriptional activities through regulation of p53-DNA binding activity. Cancer Res. 2007;67(7):3145-52.

68. Romanov VS, Pospelov VA, Pospelova TV. Cyclin-dependent kinase inhibitor p21(Waf1): contemporary view on its role in senescence and oncogenesis. Biochemistry (Mosc). 2012;77(6):575-84.

69. Wang H, Zhu LJ, Yang YC, Wang ZX, Wang R: MiR-224 promotes the chemoresistance of human lung adenocarcinoma cells to cisplatin via regulating G/S transition and apoptosis by targeting p21. Br J Cancer. 2014;111(2):339-54.

70. Qu K, Lin T, Wei J, Meng F, Wang Z, Huang Z, et al. Cisplatin induces cell cycle arrest and senescence via upregulating P53 and P21 expression in HepG2 cells. Nan Fang Yi Ke Da Xue Xue Bao. 2013;33(9):1253-9.

71. Cai G, Wang J, Xin X, Ke Z, Luo J. Phosphorylation of glycogen synthase kinase-3 beta at serine 9 confers cisplatin resistance in ovarian cancer cells. Int J Oncol. 2007;31(3):657-62.

72. Gao Y, Liu Z, Zhang X, He J, Pan Y, Hao F, et al. Inhibition of cytoplasmic GSK-3beta increases cisplatin resistance through activation of Wnt/betacatenin signaling in A549/DDP cells. Cancer Lett. 2013;336(1):231-9.

73. Erovic BM, Pelzmann M, Grasl M, Pammer J, Kornek G, Brannath W, et al. Mcl-1, vascular endothelial growth factor-R2, and 14-3-3sigma expression might predict primary response against radiotherapy and chemotherapy in patients with locally advanced squamous cell carcinomas of the head and neck. Clin Cancer Res. 2005;11(24 Pt 1):8632-6.

74. Han JY, Hong EK, Choi BG, Park JN, Kim KW, Kang JH, et al. Death receptor 5 and $\mathrm{BCl}-2$ protein expression as predictors of tumor response to gemcitabine and cisplatin in patients with advanced non-small-cell lung cancer. Med Oncol. 2003;20(4):355-62

75. Michaud WA, Nichols AC, Mroz EA, Faquin WC, Clark JR, Begum S, et al. BCl-2 blocks cisplatin-induced apoptosis and predicts poor outcome following chemoradiation treatment in advanced oropharyngeal squamous cell carcinoma. Clin Cancer Res. 2009;15(5):1645-54.

76. Williams J, Lucas PC, Griffith KA, Choi M, Fogoros S, Hu YY, et al. Expression of BCl-XL in ovarian carcinoma is associated with chemoresistance and recurrent disease. Gynecol Oncol. 2005;96(2):287-95. 
77. Jain $\mathrm{HV}$, Meyer-Hermann M. The molecular basis of synergism between carboplatin and ABT-737 therapy targeting ovarian carcinomas. Cancer Res. 2011;71(3):705-15.

78. Yu B, Yang X, Xu Y, Yao G, Shu H, Lin B, et al. Elevated expression of DKK1 is associated with cytoplasmic/nuclear beta-catenin accumulation and poor prognosis in hepatocellular carcinomas. J Hepatol. 2009;50(5):948-57.

Submit your next manuscript to BioMed Central and take full advantage of:

- Convenient online submission

- Thorough peer review

- No space constraints or color figure charges

- Immediate publication on acceptance

- Inclusion in PubMed, CAS, Scopus and Google Scholar

- Research which is freely available for redistribution 